\title{
GH97 is a new family of glycoside hydrolases, which is related to the $\alpha$-galactosidase superfamily Daniil G Naumoff
}

\author{
Address: Laboratory of Bioinformatics, State Institute for Genetics and Selection of Industrial Microorganisms, I-Dorozhny proezd, 1, Moscow \\ 117545, Russia \\ Email: Daniil G Naumoff - daniil_naumoff@yahoo.com
}

Published: 30 August 2005

BMC Genomics 2005, 6:1 12 doi:10.1|86/|47|-2|64-6-1/2

This article is available from: http://www.biomedcentral.com/I47/-2/64/6/II2

(c) 2005 Naumoff; licensee BioMed Central Ltd.

This is an Open Access article distributed under the terms of the Creative Commons Attribution License (http://creativecommons.org/licenses/by/2.0), which permits unrestricted use, distribution, and reproduction in any medium, provided the original work is properly cited.
Received: 2I March 2005

Accepted: 30 August 2005

\begin{abstract}
Background: As a rule, about $1 \%$ of genes in a given genome encode glycoside hydrolases and their homologues. On the basis of sequence similarity they have been grouped into more than ninety GH families during the last 15 years. The GH97 family has been established very recently and initially included only 18 bacterial proteins. However, the evolutionary relationship of the genes encoding proteins of this family remains unclear, as well as their distribution among main groups of the living organisms.
\end{abstract}

Results: The extensive search of the current databases allowed us to double the number of GH97 family proteins. Five subfamilies were distinguished on the basis of pairwise sequence comparison and phylogenetic analysis. Iterative sequence analysis revealed the relationship of the GH97 family with the $\mathrm{GH} 27, \mathrm{GH} 3 \mathrm{I}$, and $\mathrm{GH} 36$ families of glycosidases, which belong to the $\alpha$-galactosidase superfamily, as well as a more distant relationship with some other glycosidase families (GHI3 and $\mathrm{GH} 20)$.

Conclusion: The results of this study show an unexpected sequence similarity of GH97 family proteins with glycoside hydrolases from several other families, that have $(\beta / \alpha)_{8}$-barrel fold of the catalytic domain and a retaining mechanism of the glycoside bond hydrolysis. These data suggest a common evolutionary origin of glycosidases representing different families and clans.

\section{Background}

On the basis of sequence similarity, glycoside hydrolases (or glycosidases, EC3.2.1.-) have been grouped into 96 families (GH1-GH100, except GH21, GH40, GH41, and GH60) by the Carbohydrate-Active Enzymes (CAZy) classification $[1,2]$. In the case of poly-domain proteins each catalytic domain is considered separately. A family was initially defined as a group of at least two sequences displaying significant amino acid similarity and with no significant similarity with other families [1]. Later, some related families of glycosidases have been combined into clans $[3,4]$. According to its definition, a clan is a group of families that are thought to have a common ancestry and are recognized by significant similarities in tertiary structure together with conservation of the catalytic residues and a catalytic mechanism [3]. Glycosidases catalyze hydrolysis of the glycosidic bond of their substrates via two general mechanisms, leading to either inversion or overall retention of the anomeric configuration at the cleavage point [4-6]. Currently, 14 clans (GH-A-GH-N) are described, and in total they contain 46 families [2]. Families of four clans (GH-A, GH-D, GH-H, and GH-K), as well as several other families, that have not been assigned to any clan, contain proteins with a similar $(\beta /$ 
$\alpha)_{8}$-barrel fold of the catalytic domain [2]. Several glycosidases, that do not have any homologues, are included into a group of non-classified glycoside hydrolases $[1,2]$. In several instances, proteins from this group have been reclassified into new families when their homologues were found [7].

Two different clans have never been merged in the CAZy classification [2], even after their significant similarity has been established. Instead, related clans (and families) having statistically significant sequence similarity of the corresponding proteins were proposed to be grouped into superfamilies at a higher hierarchical level. For example, we have described the furanosidase ( $\beta$-fructosidase) superfamily, that includes clans GH-F (inverting glycosidases) and GH-J (retaining glycosidases), as well as the GHLP (COG2152) family of enzymatically-uncharacterized proteins [8-11].

Nowadays, some families are very large. For example, GH13 family (clan GH-H) includes more than 2,000 representatives [2]. This large and poly-specific group of enzymes has been studied by many authors [12-19]. In particular, it was shown that splitting of this family into smaller subfamilies allowed to clarify the relationship of its members $[12,13]$.

The majority of known glycosidases with the $\alpha$-galactosidase activity [EC3.2.1.22] belong to families GH27 and GH36, that form clan GH-D $[2,20]$. This clan and family GH31 compose the $\alpha$-galactosidase superfamily [21-24]. This superfamily has a distant relationship with clan GH$\mathrm{H}[25,26]$, which we have proposed to name the $\alpha$-glucosidase superfamily [24]. Both superfamilies contain proteins sharing the same enzymatic mechanism (retention), a similar $(\beta / \alpha)_{8}$-barrel fold of the catalytic domain [2], and use substrates only with the axial orientation of the glycosidic bond [4].

Gram-negative obligate anaerobe Bacteroides thetaiotaomicron ATCC29148 is a commensal bacterium found in the human colon where it ferments a wide variety of polysaccharides $[27,28]$. Its starch utilization system (sus) has been studied in detail [29-35]. One of the corresponding loci (Figure 1) includes divergently oriented regulatory gene susR and seven structural genes susA-susG [30-34]. Genes susC-susF encode outer membrane proteins are involved in starch binding. Glycosidases SusA (a neopullulanase, EC 3.2.1.135) and SusG (an $\alpha$-amylase, EC 3.2.1.1) are members of family GH13 [29-32]. SusB is an unusual $\alpha$-glucosidase [EC 3.2.1.20] that for a long time was considered a unique glycosidase with no homologues $[29,30]$. Therefore it was included in the group of nonclassified glycoside hydrolases [2]. We have found a group of its homologues among hypothetical proteins encoded by open reading frames (ORFs), that recently were sequenced in the frame of several prokaryotic genome projects. We referred to this group of proteins as the GHX family $[23,24]$. In June 2004, 18 members of this family were recognized in the CAZy classification as the GH97 family of glycoside hydrolases. Currently (June 2005), family GH97 includes two $\alpha$-glucosidases SusB from closely related bacteria $B$. thetaiotaomicron ATCC29148 and Tannerella forsythensis (Bacteroides forsythus) ATCC43037, as well as 22 hypothetical proteins encoded by ORFs [2].

In this work we updated the GH97 family of glycosidases, performed its phylogenetic analysis, and established its evolutionary relationship with several other glycosidase families.

\section{Results and discussion Collecting sequences of family $\mathrm{GH} 97$}

PSI-BLAST search of the non-redundant database with the Bacteroides thetaiotaomicron $\alpha$-glucosidase SusB (97A1_BACTH, see Table I) as a query sequence yielded 32 protein sequences with the worst (the largest) $E$-value of $2 \times 10^{-20}$ during the first round. Among them we found 10 paralogous proteins from $B$. thetaiotaomicron ATCC29148 and their 22 homologues from other species. Among 32 obtained proteins were found all 24 members of the GH97 family listed at the CAZy server [2]. Genomic BLAST revealed 13 additional homologous sequences. Based on the sequence similarity, we propose to enlarge the GH97 family by including all known homologues of SusB. As a result, currently this family includes 45 proteins. The majority of them represent Eubacteria (16 different species). Three other sequences correspond to Archaea (Haloarcula marismortui) and two uncultured bacteria. Four sequences are annotated in the NCBI database as eukaryotic (Anopheles gambiae) genome fragments. Only five out of 45 protein sequences (from Anopheles and an uncultured bacterium) are short fragments (Table I).

PSI-BLAST searches with a few randomly selected divergent representatives of the GH97 family used as a query sequence during the first round always yielded the same 32 protein sequences as with 97A1_BACTH. An analysis of the order of the sequence appearance during the first round of searches by PSI-BLAST, depending on the query, allows us to distinguish five subfamilies $(97 a-97 e)$ in the GH97 family with at least two known members in each of them (Table I). The obtained pairwise alignments were used for generating the protein multiple sequence alignment of family GH97. The most conserved parts of the alignment are shown on Figure 2.

The fragment of Leifsonia xyli СТСВ07 genome [GenBank: NC_006087] revealed by Genomic BLAST has 2 stop 


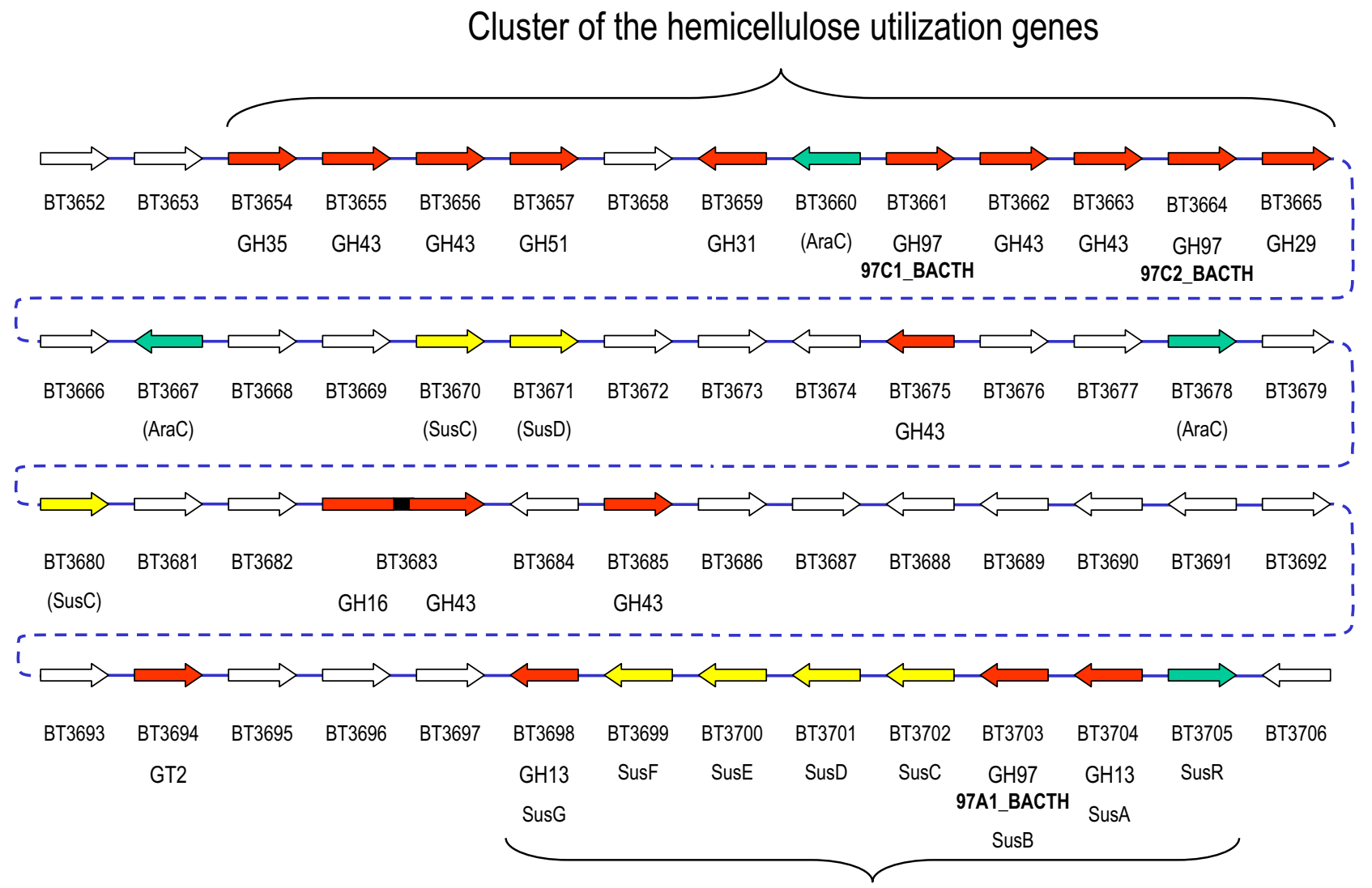

Cluster of the starch utilization genes sus

\section{Figure I}

Structure of Bacteroides thetaiotaomicron ATCC29 I 48 genome fragment containing gene clusters for starch and hemicellulose utilization. Arrows indicate the direction of gene transcription. Red arrows correspond to glycosidase $(\mathrm{GH})$ and glycosyltransferase (GT) genes: family belonging is indicated. Yellow arrows correspond to genes coding outer membrane proteins involved in starch binding (susC-susF) and their homologues. Green arrows correspond to genes of the transcriptional activator SusR and predicted transcriptional regulators homologous to AraC.

codons in the region homologous to genes of GH97 family proteins. An analysis of the nucleic acid sequence allowed us to detect a frame shift (data not shown). The improved ORF encodes protein sequence (97C1_LEIXY), showing a significant sequence similarity with the other members of family GH97 along its whole length (Figure 2 ). However, it was impossible to determine the very beginning of the protein sequence including the start codon. This protein is a divergent representative of the GH97 family and it could not be classified into any subfamily on the basis of pairwise sequence comparison. 97C1_LEIXY and its closest homologue 97D1_CAUCR (Evalue $=2 \times 10^{-54}$ ) have only $30 \%$ of sequence identity.
A short gene fragment [GenBank: AY350337] from an uncultured bacterium was revealed by Genomic BLAST. It had been obtained and sequenced during PCR screening of human gut microflora [36]. The deduced protein sequence (97A2_UNBAC) corresponds to the C-terminal part of the others GH97 family proteins and has the highest similarity level with 97A1_BACTH (63\% of sequence identity) and 97A1_TANFO (60\%). It allows us to include this protein fragment into subfamily 97a (Table I).

PSI-BLAST search of the non-redundant protein database yielded a unique eukaryotic protein fragment [GenPept: EAL42226] homologous to GH97 family proteins. Screen- 
Table I: Glycoside hydrolases analyzed in the work

\begin{tabular}{|c|c|c|c|c|c|}
\hline Name & $\begin{array}{l}\text { Family, } \\
\text { subfamily }\end{array}$ & Organism & $\begin{array}{l}\text { Accession } \\
\text { number }\end{array}$ & Protein function (annotation) & Length $^{\mathrm{b}}$ \\
\hline 97AI_BACTH & GH97, 97a & Bacteroides thetaiotaomicron VPI-5482 = ATCC29| 48 & AAC4467I & alpha-glucosidase SusB & 738 \\
\hline 97A3_BACTH & GH97, 97a & Bacteroides thetaiotaomicron VPI-5482 $=$ ATCC29| 48 & AAO75790 & ORF: alpha-glucosidase & 671 \\
\hline 97BI_BACTH & $\mathrm{GH} 97,97 \mathrm{~b}$ & Bacteroides thetaiotaomicron VPI-5482 $=$ ATCC29| 48 & AAO76978 & ORF: putative alpha-glucosidase & 662 \\
\hline 97B2_BACTH & GH97, 97b & Bacteroides thetaiotaomicron VPI-5482 $=$ ATCC29148 & AAO78400 & ORF: putative alpha-glucosidase & 650 \\
\hline 97CI_BACTH & GH97, 97c & Bacteroides thetaiotaomicron VPI-5482 $=$ ATCC29| 48 & AAO78766 & ORF: alpha-glucosidase & 647 \\
\hline 97C2_BACTH & $\mathrm{GH} 97,97 \mathrm{c}$ & Bacteroides thetaiotaomicron VPI-5482 = ATCC29| 48 & AAO78769 & ORF: putative alpha-glucosidase & 638 \\
\hline 97EI_BACTH & $\mathrm{GH} 97,97 \mathrm{e}$ & Bacteroides thetaiotaomicron VPI-5482 $=$ ATCC29| 48 & AAO75239 & ORF: putative alpha-glucosidase & 644 \\
\hline 97AI_BACFR & GH97, 97a & Bacteroides fragilis $\mathrm{YCH} 46$ & BAD4794I & ORF: alpha-glucosidase & 719 \\
\hline 97A2_BACFR & $\mathrm{GH} 97,97 \mathrm{a}$ & Bacteroides fragilis $\mathrm{YCH} 46$ & BAD48072 & ORF: alpha-glucosidase & 671 \\
\hline 97BI_BACFR & $\mathrm{GH} 97,97 \mathrm{~b}$ & Bacteroides fragilis $\mathrm{YCH} 46$ & BAD50730 & ORF: putative alpha-glucosidase & 649 \\
\hline 97BI_PRERU & $\mathrm{GH} 97,97 \mathrm{~b}$ & Prevotella ruminicola 23 & (TIGR_26473I) & ORF & 645 \\
\hline 97B2_PRERU & $\mathrm{GH} 97,97 \mathrm{~b}$ & Prevotella ruminicola 23 & (TIGR_26473I) & ORF & 658 \\
\hline 97CI_PRERU & GH97, 97c & Prevotella ruminicola 23 & (TIGR_26473I) & ORF & 621 \\
\hline 97C2_PRERU & $\mathrm{GH} 97,97 \mathrm{c}$ & Prevotella ruminicola 23 & (TIGR_26473I) & ORF & 639 \\
\hline 97C3_PRERU & $\mathrm{GH} 97,97 \mathrm{c}$ & Prevotella ruminicola 23 & (TIGR_26473I) & ORF & 645 \\
\hline 97AI_SALRU & GH97, 97a & Salinibacter ruber DSMI 3855 & $\left(\mathrm{NC} \_006812\right)$ & ORF & 708 \\
\hline 97AI_AZOVI & GH97, 97a & Azotobacter vinelandii AvOP & EAM07225 & ORF: alpha-glucosidase & 673 \\
\hline 97AI_XANAX & GH97, 97a & Xanthomonas axonopodis pv. citri 306 & AAM37448 & ORF: alpha-glucosidase & 693 \\
\hline 97DI_XANAX & GH97, 97d & Xanthomonas axonopodis pv. citri 306 & AAM38I56 & ORF: alpha-glucosidase & 654 \\
\hline 97AI_XANCA & $\mathrm{GH} 97,97 \mathrm{a}$ & Xanthomonas campestris pv. campestris ATCC 33913 & AAM4I744 & ORF: alpha-glucosidase & 692 \\
\hline 97DI_XANCA & $\mathrm{GH} 97,97 \mathrm{~d}$ & Xanthomonas campestris pv. campestris ATCC 33913 & AAM42433 & ORF: alpha-glucosidase & 654 \\
\hline 97AI_MICDE & $\mathrm{GH} 97,97 \mathrm{a}$ & Microbulbifer (Saccharophagus) degradans $2-40$ & ZP_003I5606 & ORF: hypothetical protein & 684 \\
\hline 97AI_SPHAL & $\mathrm{GH} 97,97 \mathrm{a}$ & Sphingopyxis alaskensis RB2256 & EAN 45679 & ORF: alpha-glucosidase & 680 \\
\hline 97DI_CAUCR & GH97, 97d & Caulobacter crescentus CBI5 & AAK2278I & ORF: putative alpha-glucosidase & 670 \\
\hline 97AI_ERYLI & $\mathrm{GH} 97,97 \mathrm{a}$ & Erythrobacter litoralis HTCC2594 & EAL74063 & ORF: alpha-glucosidase & 681 \\
\hline 97EI_RHOBA & GH97, 97e & Rhodopirellula baltica SHI (Pirellula sp. I) & CAD78916 & ORF: alpha-glucosidase & 645 \\
\hline 97CI_LEIXY & $\mathrm{GH} 97,97 \mathrm{c}$ & Leifsonia xyli subsp. xyli СТСВ07 & $\left(\mathrm{NC} \_006087\right)^{*}$ & ORF: similar to alpha-glucosidase & $775^{*}$ \\
\hline 97XI_SOLUS & GH97 & Solibacter usitatus Ellin6076 & EAM58489 & ORF: hypothetical protein & 619 \\
\hline 97AI_HALMA & $\mathrm{GH} 97,97 \mathrm{a}$ & Haloarcula marismortui ATCC43049 & AAV45265 & ORF: alpha-glucosidase & 1144 \\
\hline 97AI_ANOGA & $\mathrm{GH} 97,97 \mathrm{a}$ & Anopheles gambiae str. PEST (African malaria mosquito) & $(\mathrm{AAAB} 01006 \mathrm{I65})$ & ORF & $380 *$ \\
\hline 97A2_ANOGA & $\mathrm{GH} 97,97 \mathrm{a}$ & Anopheles gambiae str. PEST (African malaria mosquito) & (AAAB0I 064948) & ORF & $209 *$ \\
\hline 97A3_ANOGA & $\mathrm{GH} 97,97 \mathrm{a}$ & Anopheles gambiae str. PEST (African malaria mosquito) & (AAABOI020II0) & ORF & $231^{*}$ \\
\hline 97A4_ANOGA & $\mathrm{GH} 97,97 \mathrm{a}$ & Anopheles gambiae str. PEST (African malaria mosquito) & (AAAB0I068263) & ORF & $229 *$ \\
\hline 97AI_UNBAC & GH97, 97a & uncultured murine large bowel bacterium $\mathrm{BAC} / \mathrm{B}$ & AAXI6382 & ORF: alpha-glucosidase & 720 \\
\hline 97A2_UNBAC & GH97, 97a & uncultured bacterium & (AY350337) & ORF & $106^{*}$ \\
\hline 97AI_ENSEQ & GH97, 97a & environmental sequence (cf. Shewanella SAR-I) & EAJ06|44* & ORF: unknown & 703 \\
\hline 97A2_ENSEQ & GH97, 97a & environmental sequence (cf. Shewanella SAR-2) & EAI69763 & ORF: unknown & 699 \\
\hline 97A3_ENSEQ & GH97, 97a & environmental sequence & EAJ75652 & ORF: unknown & 714 \\
\hline 97A4_ENSEQ & $\mathrm{GH} 97,97 \mathrm{a}$ & environmental sequence & EAI5I 202 & ORF: unknown & 713 \\
\hline 97A5_ENSEQ & $\mathrm{GH} 97,97 \mathrm{a}$ & environmental sequence & EAI80962 & ORF: unknown & $702 *$ \\
\hline
\end{tabular}


Table I: Glycoside hydrolases analyzed in the work (Continued)

\begin{tabular}{|c|c|c|c|c|c|}
\hline 97A6_ENSEQ & GH97, 97a & environmental sequence & $\begin{array}{l}\text { EAH928II, } \\
\text { EAI03708, } \\
\text { EAD44407, } \\
\text { EAG79875, } \\
\text { EAH928I9, } \\
\text { EAI36772 }\end{array}$ & ORF: unknown & $7 I I$ \\
\hline 97A7_ENSEQ & GH97, 97a & environmental sequence & $\begin{array}{l}\text { EAJ99185, } 89 \text { EAD } 99255, \\
\text { EAH48404, } \\
\text { EAH57728, } \\
\text { EAD83763, } \\
\text { EAH0498I, } \\
\text { EAC9I } 563 \text {, } \\
\text { EAH85977, } \\
\text { EAD II } 1728\end{array}$ & ORF: unknown & 710 \\
\hline 97A8_ENSEQ & GH97, 97a & environmental sequence & $\begin{array}{l}\text { EAJ85380, } \\
\text { EAH8689। }\end{array}$ & ORF: unknown & $669 *$ \\
\hline 97CI_ENSEQ & GH97, 97c & environmental sequence & EAD85224* & ORF: unknown & $218^{*}$ \\
\hline GH27_ORYSA & $\mathrm{GH} 27,27 \mathrm{a}$ & Oryza sativa japonica cultivar Nipponbare (rice) & BAB 12570 & alpha-galactosidase & 417 \\
\hline
\end{tabular}

${ }^{a}$ Accession numbers of protein sequences are given according to the NCBI database [72]. Numbers of nucleic sequences are given (in parentheses) if the corresponding protein sequences have not been deposited. In some cases (asterisked), protein sequences were edited by changing the start codon.

bProtein length was established as the number of amino acids in the corresponding precursor. Incomplete sequences (protein fragments) are asterisked.

ing of the database of eukaryotic nucleic acid sequences uncovered the corresponding DNA sequence [GenBank: AAAB01006165], as well as three other short sequences [GenBank: AAAB01064948, AAAB01020110, and AAAB01068263]. All of them had been sequenced during the mosquito Anopheles gambiae genome project [37]. These 4 sequences were aligned for the identification of overlapping regions. AAAB01064948 sequence is homologous to the central part of AAAB01006165 sequence having $54 \%$ of identity at the protein level. The ends of AAAB01020110 sequence are respectively homologous to one end of AAAB01006165 and AAAB01068263 sequences: $65 \%$ and $69 \%$ sequence identity at the protein level. Thus, these 4 sequences correspond to at least two different genes. In total, they cover a complete bacterial gene encoding of a protein of family GH97. Taking into account i) a high similarity level of the 4 deduced protein sequences with bacterial proteins $(50-71 \%$ identity with 97A1_BACFR, 97A2_BACTH, 97A1_TANFO, and 97A1_BACTH), ii) the intron-free gene structure, iii) an inability to map the genes on the mosquito chromosomes, and iv) absence of GH97 family proteins in any other eukaryotic organism, we suggest the bacterial origin of these four gene fragments. The bacterial origin could have resulted from a contamination of Anopheles gambiae tissue used for preparing of genome library by mosquito Bacteroides-like gut microflora. The evidence for such kind of contamination was obtained when testing the 35,575 clones from A. gambiae cDNA library [38]. It was found that at least 808 sequences appeared to be bacterial contaminants.

In order to enlarge database of family GH97 we performed screening of the so-called "Environmental Sam- ples data" [39]. It revealed 60 nucleic acid sequences from the Sargasso Sea that are homologous to genes of GH97 family proteins. However, the majority of them encode only short protein fragments and many of them have a very high level of sequence similarity. Among them we found only 5 full-size or almost complete genes (each encodes a protein consisting of more than 650 amino acid residues). Three additional "gene" sequences were obtained by combining overlapping gene fragments with almost identical sequences (at least $95 \%$ of sequence identity at the protein level). Hypothetical proteins (97A1_ENSEQ-97A8_ENSEQ) encoded by these 8 genes should be placed in the 97a subfamily, on the basis of sequence similarity (Table I). Moreover, the majority of the incomplete genes encode protein fragments belonging to the same subfamily. Only four [GenPept: EAE76000, EAE67019, EAH16525, and EAH96685] and two [GenPept: EAE21375 and EAG68085] protein fragments correspond to subfamilies 97b and 97c, respectively. One short fragment (137 amino acids; [GenPept: EAD85224]) cannot be unambiguously classified into any subfamily of the GH97 family. An analysis of the nucleic acid sequence encoding the latter protein fragment [GenBank: AACY01501371] allowed us to extend the protein fragment by using another start codon. The resulting protein sequence (97C1_ENSEQ; 218 amino acids) shows similarity with the sequences of the other members of family GH97 along its whole length. However, it was still impossible to include this protein fragment into any subfamily on the basis of pairwise sequence comparison.

\section{Phylogenetic analysis of family $\mathrm{GH} 97$}

To check the actual relationships of proteins within the GH97 family we performed a phylogenetic analysis using 

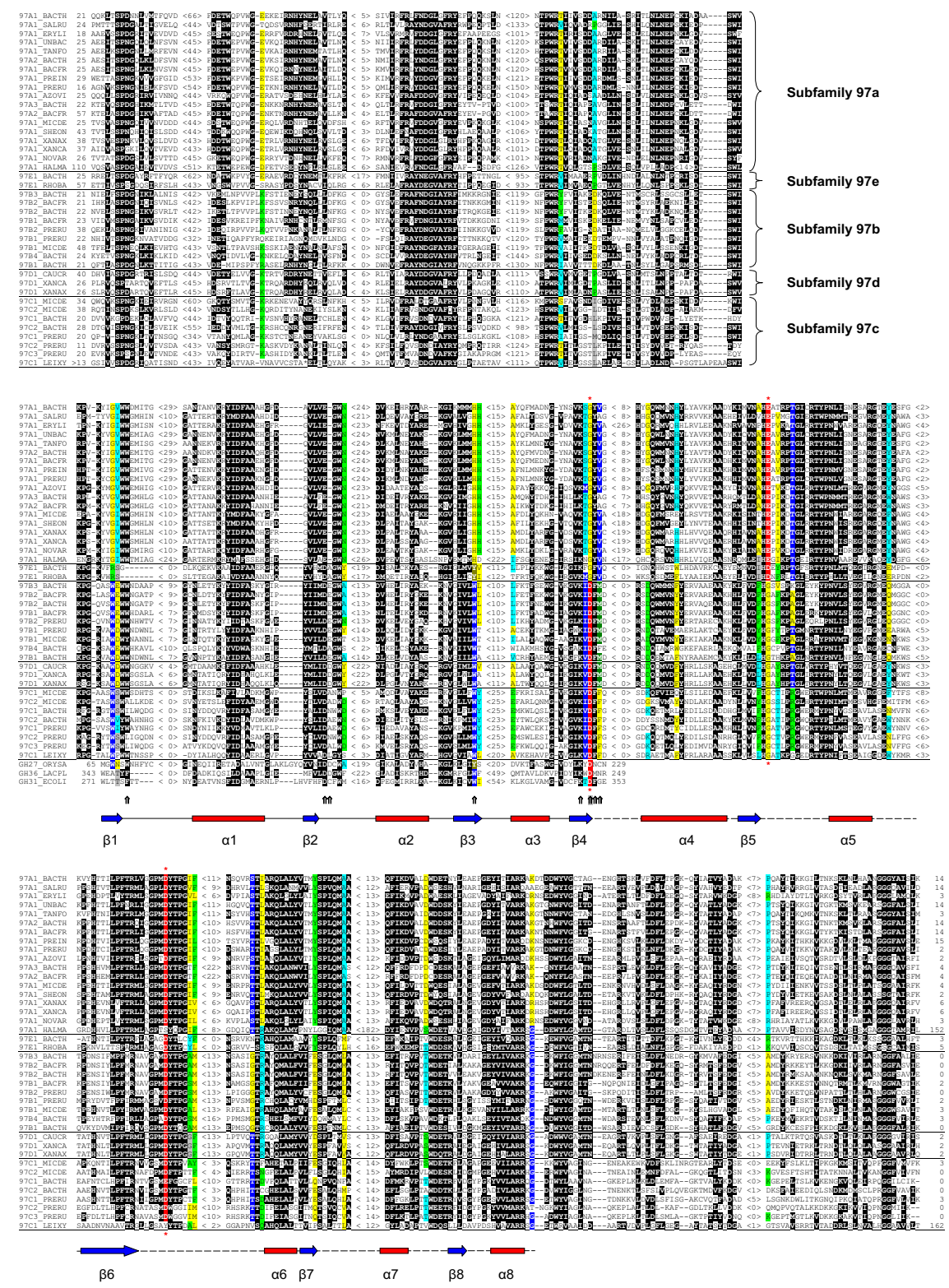

Figure 2

Portion of the multiple sequence alignment of the sequences analyzed. Ten-letter name for each sequence is indicated in the leftmost column (for origin of the sequences see Table I). The alignment continuously spans three panels. Distances to the $\mathrm{N}$ - and $\mathrm{C}$-termini and length of omitted fragments are indicated. Highly conserved residues are highlighted in sequences. Amino acid positions that are highly conserved within several subfamilies but varied in amino acid residues in different subfamilies are coloured. Subfamily belonging of sequences (for family GH97) are indicated in the most right. Amino acid residues, interacting with the substrate in the active center of $\mathrm{GH} 27$ and $\mathrm{GH} 3 \mathrm{I}$ family glycosidases, are indicated by arrows at the bottom [50-54]. The arrow on the gray background corresponds to the Asp residue, playing the role of the nucleophile in glycosidases of families $\mathrm{GH} 27$ and GH3I. Red asterisks over and under the alignment indicate three conserved positions (in red) probably corresponding to the nucleophile and proton donor in the glycosidases of family $\mathrm{GH} 97$ (see text). Alignment of GH27_ORYSA and GH3 I_ECOLI is structure-based. At the bottom of the figure, $\beta$-strands and $\alpha$-helixes of the $(\beta / \alpha)_{8}$-barrel are indicated. The first part of the barrel $(\beta \mathrm{I}-\beta 4)$ is shown according to the known structures of $\mathrm{GH} 27$ and $\mathrm{GH} 3 \mathrm{I}$ family members [5I, 54]. The second part of the barrel $(\alpha 4-\alpha 8)$ is based on generalization of predictions for several GH97 family proteins by 3D-PSSM, GOR IV, and nnpredict programs. 


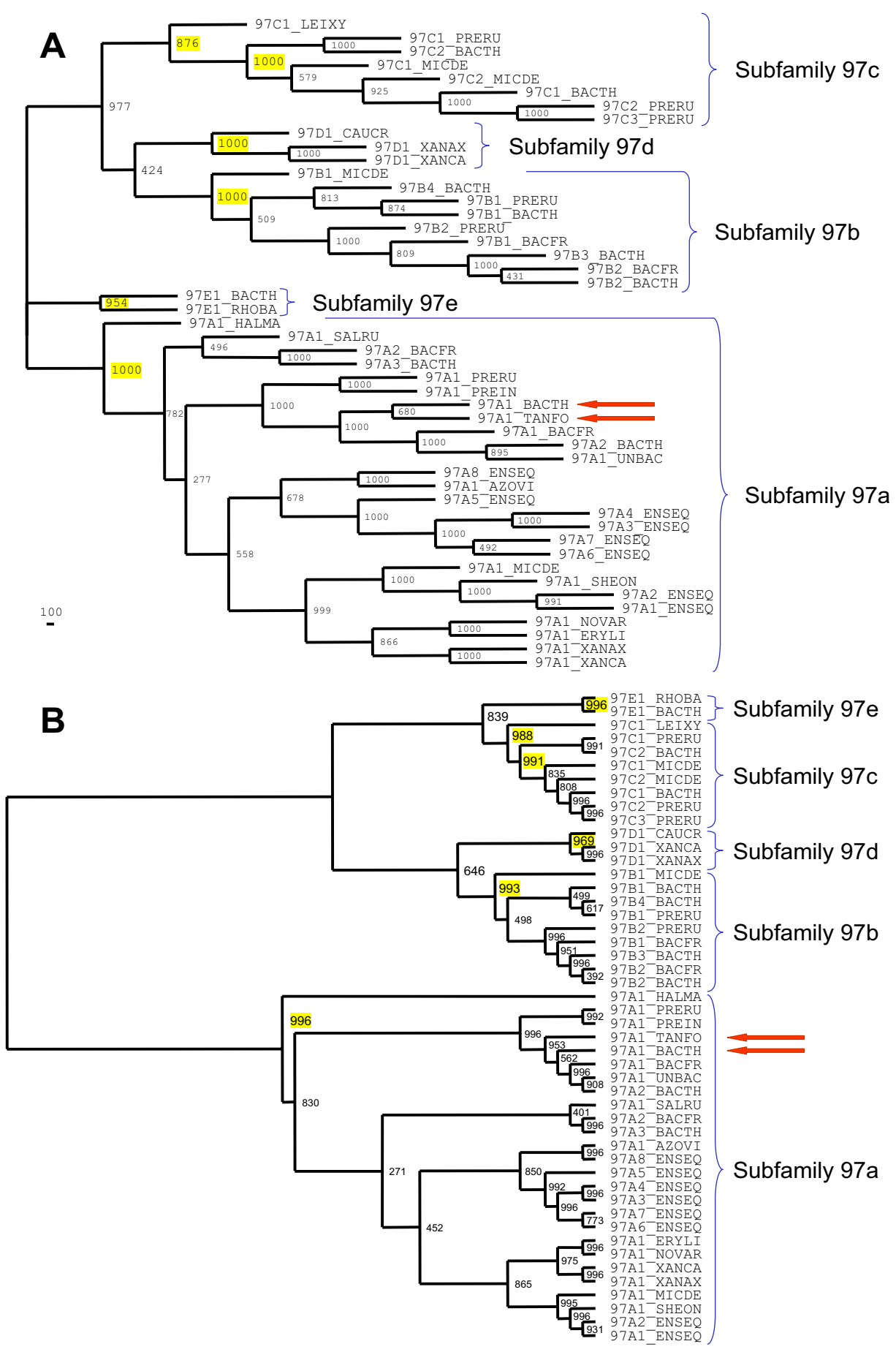

\section{Figure 3}

Phylogenetic trees of family GH97. The trees were reconstructed by the PHYLIP package. Each node was tested using the bootstrap approach and the number of supporting pseudoiterations (out of 1000) is indicated for each internal knot. Subfamily belongings of sequences are indicated, the value of bootstrap support for each subfamily is coloured in yellow. Red arrows indicate to the enzymatically-characterized proteins 97AI_BACTH and 97AI_TANFO (see text). The origin of sequences is given in Table I. (A) The maximum parsimony phylogenetic tree. The bootstrap values were determined using the maximum parsimony (PROTPARS) method. (B) The neighbor-joining phylogenetic tree. The number of amino acid substitutions per site is taken as a measure of branch length. 
known that phylogeny is the best basis for verification of subfamily structure of a protein family. In many works, where composition of a glycosidase family has been analyzed, the monophyletic status was used as the main argument for a subfamily description. Among others [40-44], this method has been applied to GH13 [12,13], GH27 $[23,24]$, and GH36 [24] families of glycoside hydrolases.

In order to verify our subdivision of the GH97 family into subfamilies we checked the clustering of the family members in the phylogenetic tree. The maximum parsimony (MP; Figure 3A) and the neighbor-joining (NJ; Figure 3B) trees have very similar topology, suggesting the correct interpretation of the evolutionary events. When any subfamily of the GH97 family was considered as an outgroup, both MP and NJ trees showed that all other subfamilies appear to form monophyletic groups with a high bootstrap value (at least $95.4 \%$ of support at both trees). It should be noted that there is no pair of subfamilies that compose neighbor clusters on both trees with significant bootstrap support. This suggests approximately the same evolutionary distance between each pair of the subfamilies.

The archaeal protein 97A1_HALMA is a clear outlayer in the cluster of subfamily 97 a at MP and NJ trees (Figure 3 ). The other members of this subfamily compose several subclusters, that include representatives either from Bacteroidetes or Proteobacteria phyla.

Unclassified protein 97C1_LEIXY is the closest neighbor of subfamily 97c cluster at MP and NJ trees (Figure 3 ) and therefore it can be considered as a divergent representative of this subfamily (Table I). Phylogenetic analysis of 97C1_ENSEQ protein fragment (data not shown) allowed us to place it into the same subfamily $97 \mathrm{c}$.

An analysis of the GH97 family multiple sequence alignment revealed a number of amino acid positions that are highly conserved within several subfamilies but varied in amino acid residues in different subfamilies (Figure 2). Taken together, these signature sequence positions allow to predict the subfamily belonging of a protein sequence.

\section{Relationship of family GH97 with some other glycosidase families}

Depending on the GH97 query and the statistical significance threshold of E-value, during the second or third PSIBLAST iterations, as a rule, we detected statistically significant similarities with $\alpha$-galactosidases. They represent families GH27 and GH36 of clan GH-D (the $\alpha$-galactosidase superfamily). More distant similarities were found with glycosidases of family GH31 (the $\alpha$-galactosidase superfamily) and in some cases with enzymaticallyuncharacterized proteins from COG0535. COG0535 has been annotated as a family of predicted Fe-S oxidoreductases, like the closest COG0641 [45]. Our BLAST searches show, that both COG families are related to the radical SAM superfamily of Fe-S enzymes [46], having $(\beta / \alpha)_{8}$-barrel fold [PDB: 1R30].

When we used some representatives of subfamily 97 a (for example, 97A1_BACTH) as a query and an E-value cut-off of 0.01 , it was possible to reveal statistically significant similarity with glycosidases of family GH20 (clan GH-K). A similarity with proteins of this family was detected after the second PSI-BLAST iteration, while the next one or two iterations revealed a distant relationship with members of COG0296 (family GH13 of clan GH-H). It should be noted that glycosidases from the clans GH-D, GH-H, and GH-K have a similar $(\beta / \alpha)_{8}$-barrel fold of their catalytic domain and the same molecular mechanism of the hydrolyzing reaction [2]. Thus, our results agree with the data of several authors $[20,25,47-49]$ showing the relationship of glycosidases from GH13, GH27, GH31, and GH36 families. More detail analysis of these families and their relationship was done by Rigden [26].

Using the $\alpha$-galactosidases from rice (GH27_ORYSA, family GH27) and Lactobacillus plantarum (GH36_LACPL, family GH36) as a query sequence for PSI-BLAST searches we found their homology with some representatives of the GH97 family (for example, 97B1_BACFR and 97B2_BACTH) after two or three iterations. However, a statistically significant sequence similarity of GH97 family proteins with $\alpha$-galactosidases is restricted to a fragment of about 100-150 amino acid residues (Figure 2). This fragment corresponds to the N-terminal half of the catalytic $(\beta / \alpha)_{8}$-barrel domain of glycosidases from the $\alpha$ galactosidase superfamily [50-54]. This half of the domain is known to be more conserved than the C-terminal half [26]. Therefore, we can assume that the catalytic domain of the GH97 family proteins also has a similar $(\beta /$ $\alpha)_{8}$-barrel fold.

In order to check whether the whole $(\beta / \alpha)_{8}$-barrel domain is present in GH97 family proteins, we tried to reconstruct their secondary and tertiary structure. The SWISS-MODEL program failed to unambiguously predict the type of the tertiary structure. The 3D-PSSM, GOR IV, and nnpredict programs were used for prediction of the protein secondary structure. The results obtained suggest that the central part of the GH97 family protein sequences represents a typical and complete $(\beta / \alpha)_{8}$-barrel domain (Figure 2). The $\mathrm{N}$ - and C-terminal parts of the sequences, mainly consisting of $\beta$-strands, most probably form two additional non-catalytic domains with an unknown function. However, different programs produce contradictory results regarding the number and exact location of the $\beta$-strands (data not shown). The non-catalytic domains of glycosi- 
dases from the $\alpha$-galactosidase and $\alpha$-glucosidase superfamilies are also predominantly composed of $\beta$-strands. At least some of these domains are involved in oligomerization and carbohydrate binding $[2,54]$.

3D-PSSM searches of the PDB database with several GH97 family proteins used as a query sequence yielded the highest level of similarity with the GH27 family glycosidases [PDB: 1KTB, 1BFM, 1R46, and 1UAS]. Among other best hits we have found representatives of several other $(\beta / \alpha)_{8^{-}}$ barrel fold glycoside hydrolase families: GH2 (clan GHA), GH5 (GH-A), GH13 (GH-H), GH17 (GH-A), GH18 $(\mathrm{GH}-\mathrm{K})$, and $\mathrm{GH} 20(\mathrm{GH}-\mathrm{K})$, as well as some other enzymes with $(\beta / \alpha)_{8}$-barrel fold, for example Bacillus subtilis inositol utilization protein IolI [PDB: 1I6N]. These results are in agreement with the hypothesis about common origin of all $(\beta / \alpha)_{8}$-barrel protein domains, that evolved from an ancestral $(\beta / \alpha)_{4}$ half-barrel by a tandem gene duplication followed by a fusion [55-60].

In all known glycosidases with the $(\beta / \alpha)_{8}$-barrel fold, the amino acid residues involved in the active center are located on the C-termini of the $\beta$-strands [61], a similar location of the active site was found in many other $(\beta / \alpha)_{8^{-}}$ barrel fold enzymes [60]. It is well known that two acidic groups (Asp and/or Glu) are almost always involved in the glycosidase active center, playing the roles of nucleophile and proton donor [4-6]. Their sequence location has been determined for several representatives of the GH27 and GH31 families [54,62-69].

The Asp residue, playing the role of nucleophile, is located on the C-terminus of the fourth $\beta$-strand of the barrel. This residue is highly conserved among proteins of the $\alpha$ galactosidase superfamily $[23,26]$. The homologous residue in the GH97 family proteins is more variable, being Asp in all members of three subfamilies $(97 b, 97 c$, and 97d) and Gly in the other proteins (subfamilies 97a and 97e), including 97A1_BACTH and 97A1_TANFO (Figure $2)$. Since these two proteins display the $\alpha$-glucosidase activity $[29,30,70]$ we can conclude that a residue, set in another site, plays the role of nucleophile at least in some proteins of the GH97 family. It should be noted that we have found a residue on the C-terminus of the fifth $\beta$ strand in GH97 family sequences that is Gly in $97 \mathrm{~b}, 97 \mathrm{c}$, and 97d subfamilies, but Glu and Asp in subfamilies 97a and 97 e respectively (Figure 2). Therefore, this residue can be suggested as a possible nucleophile in glycosidases of $97 \mathrm{a}$ and $97 \mathrm{e}$ subfamilies. As a rule, the catalytically essential residues are highly conserved among enzymatically active members of a glycoside hydrolase family, being either Asp, or Glu. The distance between the carboxylic groups of the nucleophile and the proton donor should be similar in order to keep the catalytic machinery. Thus, the difference in the predicted nucleophile residue between 97a and 97e subfamilies is unexpected. However, this does not exclude the existence of a glycosidase activity in proteins with Asp residue at the fifth $\beta$-strand (subfamily 97e). To illustrate, in the GH32 family the Asp residue was experimentally shown to be the nucleophile, while several proteins of this family have Glu residue at the homologous position and at least some of them are catalytically active $[10,11]$.

The proton donor of families GH27 and GH31 is located on the C-terminus of the sixth $\beta$-strand of the $(\beta / \alpha)_{8}$-barrel domain. It is outside of the N-terminal half of barrel, which can be unambiguously aligned with proteins of the GH97 family. However, on the C-terminus of the sixth $\beta$ strand of the predicted $(\beta / \alpha)_{8}$-barrel of the GH97 family there is an Asp residue, which is highly conserved in all subfamilies of the family (Figure 2 ). We suggest this residue as a possible proton donor. Taking into account another structure of the active center and significant sequence similarity of only a half of the catalytic domain, the current data do not support an inclusion of the GH97 family into the $\alpha$-galactosidase superfamily.

As far as we know, 97A1_BACTH and 97A1_TANFO are the only enzymatically-characterized proteins in the GH97 family [2]. All other members of this family have been found recently during genome projects and are encoded by ORFs. Genes of this family are represented only in a limited number of Eubacteria from phyla Actinobacteria (1 genus), Bacteroidetes (4 genera), Planctomycetes ( 1 genus), and Proteobacteria ( 3 and 4 genera from $\alpha$ - and $\gamma$-classes, respectively), as well as in a unique Archaea (Haloarcula marismortui). However, many of these bacteria have several paralogous genes. The most interesting case is that of $B$. thetaiotaomicron ATCC29148, which has $\alpha$-glucosidase SusB (97A1_BACTH) and 9 putative paralogues representing four GH97 subfamilies (Table I), at least two of the paralogues (97C1_BACTH and 97C2_BACTH) are also expressed in vivo [28]. This human commensal microorganism is known as a bacterium with the highest number of glycosidase and glycosyltransferase genes $[27,71]$. Taken together, these facts we can suggest that evolution of GH97 family proteins has been associated with multiple duplications, gene elimination, and horizontal transfer.

\section{Conclusion}

The results of the sequence analysis allow us to distinguish five subfamilies in the GH97 family of glycoside hydrolases. The experimental data on the enzymatic activity are available only for two representatives of the GH97 family: $\alpha$-glucosidases 97A1_BACTH and 97A1_TANFO $[29,30,70]$. However, we suppose that the other members of this family may also possess some glycosidase activities. Our data suggest that proteins of this family have a com- 
mon evolutionary origin with glycosidases of the $\alpha$-galactosidase superfamily. Many genes, encoding proteins of the GH97 family, are located in clusters with genes of glycoside hydrolases and other carbohydrate-active enzymes. For example, 97C1_BACTH and 97C2_BACTH (subfamily $97 \mathrm{c}$ ) are encoded by genes of $B$. thetaiotaomicron located at a hemicellulose utilization locus together with eight other glycosidase genes (Figure 1). Taken together, these data support a recent suggestion to consider family GH97 (or GHX) as a new family of glycoside hydrolases $[2,24]$. The evolutionary relationship of GH97 proteins with glycosidases of the GH-D, GH-H, and GH-K (and probably GH-A) clans allows to extrapolate their common most important characteristics to glycoside hydrolases of the GH97 family. We can predict a similar $(\beta / \alpha)_{8}$-barrel fold of the catalytic domain and retaining mechanism of the glycoside bond hydrolysis for glycosidases of the GH97 family.

\section{Methods}

Protein and nucleic sequences were retrieved from the NCBI database [72]. All proteins analyzed in this work were designated by a ten-letter name (see Table I). The search for homologous proteins was done using the PSIBLAST [73] and Genomic BLAST at the NCBI server. The statistical significance threshold for including a sequence in the model ( $E$-value) used by PSI-BLAST in the next iteration was either $10^{-2}$ or $10^{-3}$, BLOSUM45 was used as a substitution matrix. Multiple sequence alignment was prepared manually using the program BioEdit [74] on the basis of BLAST pairwise alignments.

The multiple sequence alignment was used to implement classical phylogenetic inference programs, using either maximum parsimony or distance methods. Programs PROTPARS and NEIGHBOR from the PHYLIP package (version 3.6; [75]) were used. Moreover, programs SEQBOOT, PROTPARS, and CONSENSE and programs SEQBOOT, PROTDIST, NEIGHBOR, and CONSENSE were successively used to derive confidence limits, estimated by 1000 bootstrap replicates, for each node in the maximum parsimony and distance tree, respectively. The program TreeView Win32 (version 1.6.6; [76]) was used for drawing the trees.

An analysis of the order of the display sequence during searches by PSI-BLAST [73] was used for a preliminary division of a family into subfamilies. The latter was defined as a group of proteins that are displayed at the top of the list in a PSI-BLAST query results. Depending on particular criteria of the protein similarity used, the algorithm can split a family into a larger or smaller number of groups of proteins. Like in some of our previous works $[10,23,24,77]$, in this study we define a subfamily as a group of proteins that have at least $30 \%$ sequence identity.
Phylogenetic analysis was used in order to verify the obtained subfamilies and to clarify their boundaries. The monophyletic status was used as a criterion for the final definition of a subfamily.

The SWISS-MODEL modeling server [78] was used to predict the tertiary structure of proteins based on their amino acid sequences. The 3D-PSSM [79], GOR IV [80] and nnpredict [81] programs were used for prediction of the protein secondary structure. The 3D-PSSM program also was used to search the PDB database.

\section{Added in proof}

After submission of the manuscript, six new sequences of GH97 family proteins have been deposited at the NCBI database. Five of them (97A1_SHEBA, 97A1_SHEFR, 97A1_SHEDE, 97A1_SHEAM, and 97A1_SPHAL) belong to subfamily 97a (Table I). The sixth protein 97X1_SOLUS cannot be unambiguously classified into any subfamily of the GH97 family on the basis of pairwise sequence comparison, composition of the signature sequence positions, and phylogenetic analysis. Most probably it corresponds to a new subfamily.

\section{Acknowledgements}

I am grateful to Dr. Bernard Labedan (Université de Paris-Sud, France) for critical reading of an earlier version of the manuscript and a helpful discussion of the problem.

This work was supported by grants of the Russian President for young scientists (MK-I I8.2003.04 and MK-I46I.2005.4).

\section{References}

I. Henrissat B: A classification of glycosyl hydrolases based on amino acid sequence similarities. Biochem J |99|, 280:309-3|6.

2. Coutinho PM, Henrissat B: Carbohydrate-Active Enzymes server. [http://afmb.cnrs-mrs.fr/CAZY/].

3. Henrissat $B$, Bairoch $A$ : Updating the sequence-based classification of glycosyl hydrolases. Biochem J 1996, 3 I 6:695-696.

4. Henrissat B, Davies G: Structural and sequence-based classification of glycoside hydrolases. Curr Opin Struct Biol 1997, 7:637-644.

5. McCarter JD, Withers SG: Mechanisms of enzymatic glycoside hydrolysis. Curr Opin Struct Biol 1994, 4:885-892.

6. Davies G, Henrissat B: Structures and mechanisms of glycosyl hydrolases. Structure 1995, 3:853-859.

7. Henrissat B, Bairoch A: New families in the classification of glycosyl hydrolases based on amino acid sequence similarities. Biochem J 1993, 293:78|-788.

8. Naumov DG, Doroshenko VG: $\beta$-Fructosidases: a new superfamily of glycosyl hydrolases. Mol Biol (Engl Tr) 1998, 32:76I-766.

9. Naumoff DG: Conserved sequence motifs in levansucrases and bifunctional $\beta$-xylosidases and $\alpha$-L-arabinases. FEBS Lett 1999, 448: I77-179.

10. Naumoff DG: $\beta$-Fructosidase superfamily: homology with some $\alpha$-L-arabinases and $\beta$-D-xylosidases. Proteins 200I, 42:66-76.

II. Pons T, Naumoff DG, Martínez-Fleites C, Hernández L: Three acidic residues at the active site in the $\beta$-propeller architecture for the glycoside hydrolase families $32,43,62$, and 68 . Proteins 2004, 54:424-432.

12. Oslancová A, Jane.ek Š: Oligo-I, 6-glucosidase and neopullulanase enzyme subfamilies from the $\alpha$-amylase family defined by the fifth conserved sequence region. Cell Mol Life Sci 2002, 59:1945-1959. 
13. Jane.ek Š, Svensson B, MacGregor EA: Relation between domain evolution, specificity, and taxonomy of the $\alpha$-amylase family members containing a C-terminal starch-binding domain. Eur J Biochem 2003, 270:635-645.

14. Sarçabal P, Remaud-Simeon M, Willemot R, Potocki de Montalk G, Svensson B, Monsan P: Identification of key amino acid residues in Neisseria polysaccharea amylosucrase. FEBS Lett 2000, 474:33-37.

15. Berezina OV, Lunina NA, Zverlov VV, Naumoff DG, Liebl W, Velikodvorskaia GA: A cluster of Thermotoga neapolitana genes involved in the degradation of starch and maltodextins: the molecular structure of the locus. Mol Biol (Engl Tr) 2003, 37:80I-809.

16. Kuriki T, Imanaka T: The concept of the $\alpha$-amylase family: structural similarity and common catalytic mechanism. J Biosci Bioeng 1999, 87:557-565.

17. Svensson B: Protein engineering in the $\alpha$-amylase family: catalytic mechanism, substrate specificity, and stability. Plant Mol Biol 1994, 25:141-157.

18. Jane.ek Š, Lévêque E, Belarbi A, Haye B: Close evolutionary relatedness of $\alpha$-amylases from Archaea and plants. I Mol Evol 1999, 48:42I-426.

19. van der Veen BA, Uitdehaag JC, Dijkstra BW, Dijkhuizen L: Engineering of cyclodextrin glycosyltransferase reaction and product specificity. Biochim Biophys Acta 2000, I 543:336-360.

20. Dagnall BH, Paulsen IT, Saier JrMH: The DAG family of glycosyl hydrolases combines two previously identified protein families. Biochem J 1995, 3 I I:349-350.

21. Naumoff DG: Sequence analysis and classification of $\alpha$-galactosidases. International Summer School "From Genome to Life: Structural, Functional and Evolutionary Approaches" :40 [http://wwwarchbac.u-psud.fr/Meetings/cargese2002/abstracts/NAUMOFF.html] Cargèse, Corsica, France July 15-27, 2002

22. Naumoff DG: $\alpha$-Galactosidase superfamily: phylogenetic analysis and homology with some $\alpha$-glucosidases. In 5th Carbohydrate Bioengineering Meeting, University Hospital Groningen Groningen, The Netherlands:32. April 6-9, 2003

23. Naumoff DG: Phylogenetic analysis of $\alpha$-galactosidases from GH27 family. Mol Biol (Engl Tr) 2004, 38:388-399.

24. Naumoff DG: The $\alpha$-galactosidase superfamily: sequence based classification of $\alpha$-galactosidases and related glycosidases. Proceedings of The Fourth International Conference on Bioinformatics of Genome Regulation and Structure, July 25-30, 2004. Novosibirsk. Russia 1:315-318 [http://www.bionet.nsc.ru/meeting/ bgrs2004/tom I.pdf].

25. Henrissat B: Glycosidase families. Biochem Soc Trans 1998 , 26:153-156.

26. Rigden DJ: Iterative database searches demonstrate that glycoside hydrolase families $27,31,36$ and 66 share a common evolutionary origin with family 13. FEBS Lett 2002, 523:17-22.

27. Xu J, Bjursell MK, Himrod J, Deng S, Carmichael LK, Chiang HC Hooper LV, Gordon JI: A genomic view of the human-Bacteroides thetaiotaomicron symbiosis. Science 2003, 299:2074-2076.

28. Sonnenburg JL, Xu J, Leip DD, Chen C-H, Westover BP, Weatherford J, Buhler JD, Gordon Jl: Glycan foraging in vivo by an intestineadapted bacterial symbiont. Science 2005, 307:1955-1959.

29. Smith KA, Salyers AA: Characterization of a neopullulanase and an $\alpha$-glucosidase from Bacteroides thetaiotaomicron 95-I. J Bacteriol I 99I, I 73:2962-2968.

30. D'Elia JN, Salyers AA: Contribution of a neopullulanase, a pullulanase, and an $\alpha$-glucosidase to growth of Bacteroides thetaiotaomicron on starch. J Bacteriol 1996, 178:7173-7179.

31. Reeves AR, Wang GR, Salyers AA: Characterization of four outer membrane proteins that play a role in utilization of starch by Bacteroides thetaiotaomicron. I Bacteriol 1997 , 179:643-649.

32. Shipman JA, Cho KH, Siegel HA, Salyers AA: Physiological characterization of SusG, an outer membrane protein essential for starch utilization by Bacteroides thetaiotaomicron. J Bacteriol 1999, | 81:7206-72।I.

33. Cho $K H$, Salyers AA: Biochemical analysis of interactions between outer membrane proteins that contribute to starch utilization by Bacteroides thetaiotaomicron. J Bacteriol 200I, 183:7224-7230.
34. D'Elia JN, Salyers AA: Effect of regulatory protein levels on utilization of starch by Bacteroides thetaiotaomicron. J Bacteriol 1996, 178:7180-7186.

35. Cho KH, Cho D, Wang GR, Salyers AA: New regulatory gene that contributes to control of Bacteroides thetaiotaomicron starch utilization genes. J Bacteriol 200I, I 83:7198-7205.

36. Wei G, Pan L, Du H, Chen J, Zhao L: ERIC-PCR fingerprintingbased community DNA hybridization to pinpoint genomespecific fragments as molecular markers to identify and track populations common to healthy human guts. J Microbiol Methods 2004, 59:91-108.

37. Holt RA, Subramanian GM, Halpern A, Sutton GG, Charlab R, Nusskern DR, Wincker P, Clark AG, Ribeiro JM, Wides R, Salzberg SL, Loftus B, Yandell M, Majoros WH, Rusch DB, Lai Z, Kraft CL, Abril JF, Anthouard V, Arensburger P, Atkinson PW, Baden H, de Berardinis V, Baldwin D, Benes V, Biedler J, Blass C, Bolanos R, Boscus D, Barnstead M, Cai S, Center A, Chaturverdi K, Christophides GK, Chrystal MA, Clamp M, Cravchik A, Curwen V, Dana A, Delcher A, Dew I, Evans CA, Flanigan M, Grundschober-Freimoser A, Friedli L, Gu Z, Guan P, Guigo R, Hillenmeyer ME, Hladun SL, Hogan JR, Hong YS, Hoover J, Jaillon O, Ke Z, Kodira C, Kokoza E, Koutsos A, Letunic I, Levitsky A, Liang Y, Lin JJ, Lobo NF, Lopez JR, Malek JA, Mclntosh TC, Meister S, Miller J, Mobarry C, Mongin E, Murphy SD, O'Brochta DA, Pfannkoch C, Qi R, Regier MA, Remington K, Shao H, Sharakhova MV, Sitter CD, Shetty J, Smith TJ, Strong R, Sun J, Thomasova D, Ton LQ, Topalis P, Tu Z, Unger MF, Walenz B, Wang A, Wang J, Wang M, Wang X, Woodford KJ, Wortman JR, Wu M, Yao A, Zdobnov EM, Zhang H, Zhao O, Zhao S, Zhu SC, Zhimulev I, Coluzzi M, della Torre A, Roth CW, Louis C, Kalush F, Mural RJ, Myers EW, Adams MD, Smith HO, Broder S, Gardner MJ, Fraser CM, Birney E, Bork P, Brey PT, Venter JC, Weissenbach J, Kafatos FC, Collins FH, Hoffman SL: The genome sequence of the malaria mosquito Anopheles gambiae. Science 2002, 298:129-149.

38. Gomez SM, Eiglmeier K, Segurens B, Dehoux P, Couloux A, Scarpell C, Wincker P, Weissenbach J, Brey PT, Roth CW: Pilot Anopheles gambiae full-length cDNA study: sequencing and initial characterization of 35,575 clones. Genome Biol 2005, 6:R39.

39. Venter JC, Remington K, Heidelberg JF, Halpern AL, Rusch D, Eisen JA, Wu D, Paulsen I, Nelson KE, Nelson W, Fouts DE, Levy S, Knap $\mathrm{AH}$, Lomas MW, Nealson K, White O, Peterson J, Hoffman J, Parsons R, Baden-Tillson H, Pfannkoch C, Rogers YH, Smith HO: Environmental genome shotgun sequencing of the Sargasso Sea. Science 2004, 304:66-74 [http://www.ncbi.nlm.nih.gov/BLAST/Genome/ EnvirSamplesBlast.html].

40. Zona R, Chang-Pi-Hin F, O'Donohue MJ, Jane ek Š: Bioinformatics of the glycoside hydrolase family $\mathbf{5 7}$ and identification of catalytic residues in amylopullulanase from Thermococcus hydrothermalis. Eur J Biochem 2004, 27 I :2863-2872.

41. Durand A, Hughes R, Roussel A, Flatman R, Henrissat B, Juge N: Emergence of a subfamily of xylanase inhibitors within glycoside hydrolase family I8. FEBS Journal 2005, 272: I745-1755.

42. Ahn YO, Mizutani M, Saino H, Sakata K: Furcatin hydrolase from Viburnum furcatum Blume is a novel disaccharide-specific acuminosidase in glycosyl hydrolase family I. J Biol Chem 2004, 279:23405-234I4.

43. Shallom D, Golan G, Shoham G, Shoham Y: Effect of dimer dissociation on activity and thermostability of the $\alpha$-glucuronidase from Geobacillus stearothermophilus: dissecting the different oligomeric forms of family 67 glycoside hydrolases. J Bacteriol 2004, 186:6928-6937.

44. Suzuki K, Taiyoji M, Sugawara N, Nikaidou N, Henrissat B, Watanabe $\mathrm{T}$ : The third chitinase gene (chiC) of Serratia marcescens 2170 and the relationship of its product to other bacterial chitinases. Biochem J 1999, 343:587-596.

45. Tatusov RL, Koonin EV, Lipman DJ: A genomic perspective on protein families. Science 1997, 278:631-637 [http:// www.ncbi.nlm.nih.gov/COG/].

46. Sofia HJ, Chen G, Hetzler BG, Reyes-Spindola JF, Miller NE: Radical SAM, a novel protein superfamily linking unresolved steps in familiar biosynthetic pathways with radical mechanisms: functional characterization using new analysis and information visualization methods. Nucleic Acids Res 2001, 29:1097-I 106

47. Henrissat $B$, Romeu $A$ : Families, superfamilies and subfamilies of glycosyl hydrolases. Biochem J 1995, 3 I I:350-351. 
48. Margolles-Clark E, Tenkanen M, Luonteri E, Penttilä M: Three $\alpha$ galactosidase genes of Trichoderma reesei cloned by expression in yeast. Eur J Biochem 1996, 240: 104- III.

49. Naumoff DG: Sequence analysis of glycosylhydrolases: $\beta$-fructosidase and $\alpha$-galactosidase superfamilies. Glycoconj J 200 I, 18:109.

50. Garman SC, Hannick L, Zhu A, Garboczi DN: The I.9 A structure of $\alpha-\mathbf{N}$-acetylgalactosaminidase: molecular basis of glycosidase deficiency diseases. Structure 2002, 1 0:425-434.

5I. Fujimoto Z, Kaneko S, Momma M, Kobayashi H, Mizuno H: Crystal structure of rice $\alpha$-galactosidase complexed with D-galactose. I Biol Chem 2003, 278:20313-20318.

52. Garman SC, Garboczi DN: The molecular defect leading to Fabry disease: structure of human $\alpha$-galactosidase. I Mol Biol 2004, 337:319-335.

53. Golubev AM, Nagem RAP, Brandão Neto JR, Neustroev KN, Eneyskaya EV, Kulminskaya AA, Shabalin KA, Savel'ev AN, Polikarpov I: Crystal structure of $\alpha$-galactosidase from Trichoderma reese $i$ and its complex with galactose: implications for catalytic mechanism. J Mol Biol 2004, 339:4I 3-422.

54. Lovering AL, Lee SS, Kim Y-W, Withers SG, Strynadka NC): Mechanistic and structural analysis of a family 3 I $\alpha$-glycosidase and its glycosyl-enzyme intermediate. I Biol Chem 2005, 280:2I05-2II5.

55. Höcker B, Jürgens C, Wilmanns M, Sterner R: Stability, catalytic versatility and evolution of the $(\beta \alpha)_{8}$-barrel fold. Curr Opin Biotechnol 200I, I 2:376-38I.

56. Höcker B, Beismann-Driemeyer S, Hettwer S, Lustig A, Sterner R: Dissection of a $(\beta \alpha)_{8}$-barrel enzyme into two folded halves. Nat Struct Biol 2001, 8:32-36.

57. Gerlt JA, Babbitt PC: Barrels in pieces? Nat Struct Biol 200I, 8:5-7

58. Lang D, Thoma R, Henn-Sax M, Sterner R, Wilmanns M: Structural evidence for evolution of the $\beta / \alpha$ barrel scaffold by gene duplication and fusion. Science 2000, 289:।546-I550.

59. Farber GK, Petsko GA: The evolution of $\alpha / \beta$ barrel enzymes. Trends Biochem Sci 1990, 1 5:228-234.

60. Wierenga RK: The TIM-barrel fold: a versatile framework for efficient enzymes. FEBS Lett 2001, 492:193-198.

61. Nagano N, Porter CT, Thornton JM: The $(\beta / \alpha)_{8}$ glycosidases: sequence and structure analyses suggest distant evolutionary relationships. Protein Eng 200 I, I 4:845-855.

62. Quaroni A, Semenza G: Partial amino acid sequences around the essential carboxylate in the active sites of the intestina sucrase-isomaltase complex. J Biol Chem 1976, 25 I:3250-3253.

63. Hermans MMP, Kroos MA, van Beeumen J, Oostra BA, Reuser Al]: Human lysosomal $\alpha$-glucosidase. Characterization of the catalytic site. J Biol Chem 1991, 266: I3507-I35I2.

64. Iwanami S, Matsui H, Kimura A, Ito H, Mori H, Honma M, Chiba S: Chemical modification and amino acid sequence of active site in sugar beet $\alpha$-glucosidase. Biosci Biotechnol Biochem 1995 , 59:459-463.

65. Kimura A, Takata M, Fukushi Y, Mori H, Matsui H, Chiba S: A catalytic amino acid and primary structure of active site in Aspergillus niger $\alpha$-glucosidase. Biosci Biotechnol Biochem 1997, 61:1091-1098.

66. Hart DO, He S, Chany CJ, Withers SG, Sims PF, Sinnott ML, Brumer $\mathrm{H}$ : Identification of Asp- I 30 as the catalytic nucleophile in the main $\alpha$-galactosidase from Phanerochaete chrysosporium, a family 27 glycosyl hydrolase. Biochemistry 2000, 39:9826-9836.

67. Ly HD, Howard S, Shum K, He S, Zhu A, Withers SG: The synthesis, testing and use of 5-fluoro-alpha-D-galactosyl fluoride to trap an intermediate on green coffee bean $\alpha$-galactosidase and identify the catalytic nucleophile. Carbohydr Res 2000 , 329:539-547.

68. Okuyama M, Okuno A, Shimizu N, Mori H, Kimura A, Chiba S: Carboxyl group of residue Asp647 as possible proton donor in catalytic reaction of $\alpha$-glucosidase from Schizosaccharomyces pombe. Eur J Biochem 200I, 268:2270-2280.

69. Kashiwabara S, Azuma S, Tsuduki M, Suzuki Y: The primary structure of the subunit in Bacillus thermoamyloliquefaciens KPI07I molecular weight 540,000 homohexameric $\alpha$-glucosidase II belonging to the glycosyl hydrolase family $3 \mathrm{I}$. Biosci Biotechnol Biochem 2000, 64: I379-1393.

70. Hughes CV, Malki G, Loo CY, Tanner ACR, Ganeshkumar N: Cloning and expression of $\alpha$-D-glucosidase and $\mathbf{N}$-acetyl- $\beta$-glucosaminidase from the periodontal pathogen, Tannerella forsythensis (Bacteroides forsythus). Oral Microbiol Immunol 2003, 18:309-312.

7I. Coutinho PM, Stam M, Blanc E, Henrissat B: Why are there so many carbohydrate-active enzyme-related genes in plants? Trends Plant Sci 2003, 8:563-565.

72. Wheeler DL, Barrett T, Benson DA, Bryant SH, Canese K, Church DM, DiCuccio M, Edgar R, Federhen S, Helmberg W, Kenton DL, Khovayko O, Lipman DJ, Madden TL, Maglott DR, Ostell J, Pontius JU, Pruitt KD, Schuler GD, Schriml LM, Sequeira E, Sherry ST, Sirotkin K, Starchenko G, Suzek TO, Tatusov R, Tatusova TA, Wagner L, Yaschenko E: Database resources of the National Center for Biotechnology Information. Nucleic Acids Res 2005, 33:D39-45 [http://www.ncbi.nlm.nih.gov/]

73. Altschul SF, Madden TL, Schaffer AA, Zhang J, Zhang Z, Miller W, Lipman DJ: Gapped BLAST and PSI-BLAST: a new generation of protein database search programs. Nucleic Acids Res 1997, 25:3389-3402.

74. Hall TA: Bioedit: a user-friendly biological sequence alignment editor and analysis program for windows 95/98/nt. Nucleic Acids Symp Ser 1999, 41:95-98 [http://www.mbio.ncsu.edu/ BioEdit/bioedit.html].

75. Felsenstein J: PHYLIP - Phylogeny Inference Package (Version 3.2). Cladistics 1989, 5:164-I66 [http://evolution.gs.washington.edu/ phylip.html]

76. Page RDM: TREEVIEW: An application to display phylogenetic trees on personal computers. Comput Appl Biosci 1996, I 2:357-358 [http://taxonomy.zoology.gla.ac.uk/rod/treeview.html].

77. Naumoff DG, Livshits VA: Molecular structure of the Lactobacillus plantarum sucrose utilization locus: comparison with Pediococcus pentosaceus. Mol Biol (Engl Tr) 200I, 35:15-22.

78. Peitsch MC: ProMod and Swiss-Model: Internet-based tools for automated comparative protein modelling. Biochem Soc Trans 1996, 24:274-279 [http://swissmodel.expasy.org/].

79. Kelley LA, MacCallum RM, Sternberg MJ: Enhanced genome annotation using structural profiles in the program 3D-PSSM. Mol Biol 2000, 299:499-520 [http://www.sbg.bio.ic.ac.uk/ 3dpssm/].

80. Garnier J, Gibrat JF, Robson B: GOR method for predicting protein secondary structure from amino acid sequence. Methods Enzymol 1996, 266:540-553 [http://npsa-pbil.ibcp.fr/cgi-bin/ npsa automat.pl?page=npsa gor4.html].

81. Kneller DG, Cohen FE, Langridge R: Improvements in protein secondary structure prediction by an enhanced neural network. J Mol Biol 1990, 2 I 4: I7 I- 182 [http://www.cmpharm.ucsf.edu/ حnomi/nnpredict-instrucs.html].

Publish with Bio Med Central and every scientist can read your work free of charge

"BioMed Central will be the most significant development for disseminating the results of biomedical research in our lifetime. "

Sir Paul Nurse, Cancer Research UK

Your research papers will be:

- available free of charge to the entire biomedical community

- peer reviewed and published immediately upon acceptance

- cited in PubMed and archived on PubMed Central

- yours - you keep the copyright
BioMedcentral 